Document downloaded from:

http://hdl.handle.net/10251/123858

This paper must be cited as:

Vega-Fleitas, E.; Mollar García, MA.; Marí, B. (2018). Effect of guanidinium on the optical properties and structure of the methylammonium lead halide perovskite. Journal of Alloys and Compounds. 739:1059-1064. https://doi.org/10.1016/j.jallcom.2017.12.177

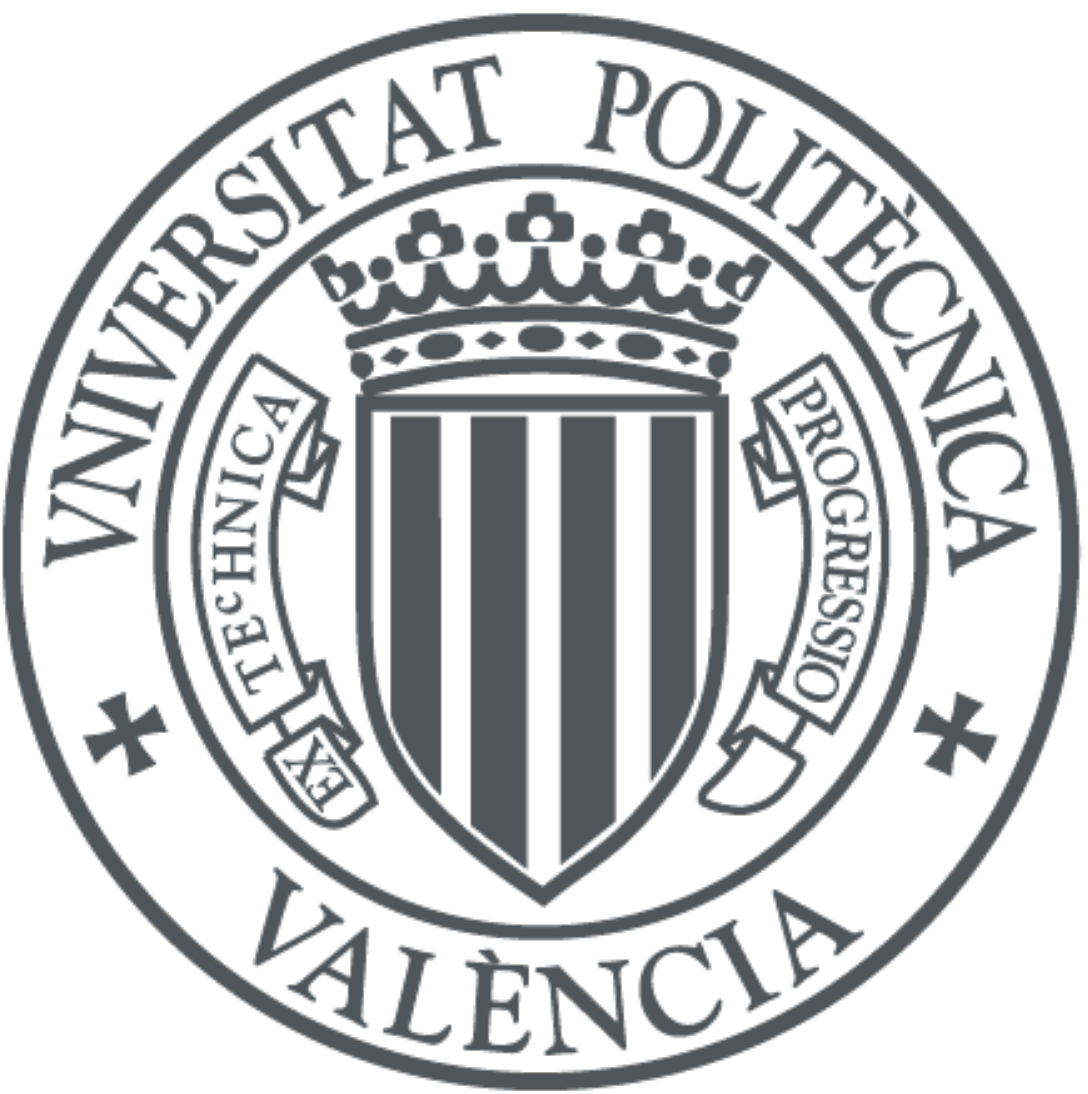

The final publication is available at

http://doi.org/10.1016/j.jallcom.2017.12.177

Copyright Elsevier

Additional Information 


\title{
Effect of Guanidinium on the Optical Properties and Structure of the Methylammonium Lead Halide Perovskite
}

\author{
Erika Vega, Miguel Mollar, Bernabé Marí \\ Institut de Disseny i Fabricació (IDF) - Universitat Politècnica de València, València, Spain. Camí \\ de Vera s/n 46022. \\ Corresponding author: Erika Vega Fleitas (ervefl@upv.es)
}

\begin{abstract}
The stability and performance of perovskite-based solar cells can be improved changing the nature of the organic cation. Herein, mixed methylammoniumguanidinium perovskites $\left(\mathrm{MA}_{1-\mathrm{x}} \mathrm{GA}_{\mathrm{x}} \mathrm{Pbl}_{3}\right)$ are structurally and optically characterized. The Pawley fit method indicates the formation of the iodide halide $\mathrm{GAPbl}_{3}$ tetragonal phase (P42_NMC). Up to $20 \%$ of the guanidinium cation was incorporated in the methylammonium lead iodide perovskite, producing a lattice enlargement, which was investigated studying the shift of the diffraction peaks of the $\mathrm{MAPbl}_{3}$ (14_CM) tetragonal lattice. Long-term stability was tested, resulting in improved mixed perovskites with a low GA content. The bandgap shifted to lower energies. The absorption bandgap diminished slightly when the GA cation substituted up to $20 \%$ of $\mathrm{MA}$ in $\mathrm{MAPbl}_{3}$, degrading when the GA amount in the mixed perovskite is larger. FESEM morphological analysis was performed showing that a uniform thin film was deposited. PL studies showed that only shallow defects had been introduced.
\end{abstract}

Keywords: Thin film perovskite, Mixed halide perovskite, Gap energy, Chemical composition, Photoluminescence. 


\section{Introduction}

The methylammonium lead halide perovskite $\left(\mathrm{CH}_{3} \mathrm{NH}_{3} \mathrm{PbX}_{3}, \mathrm{X}=\right.$ halogen; $\mathrm{CH}_{3} \mathrm{NH}_{3}=\mathrm{MA}$ ) and its mixed-halide crystals have been studied in depth in recent years, showing many optimal optoelectronic features of an ideal solar cell absorber. Among these properties, a favorable bandgap, high absorption coefficient, excellent charge mobility, high photoluminescence quantum efficiencies, small exciton binding energy, tunable bandgap and a reasonably defect tolerance [1-6] can be highlighted. These features have given perovskites an important role as an absorber in photovoltaic cells [7-11]. Indeed, in a relatively short period of time, devices based on perovskite materials have achieved a performance of certified 22.1\% PCE [12], starting from a conversion efficiency of only $3.9 \%$ in 2009 [1] and being, at the same time, more costeffective than the silicon solar ones.

When it comes to the synthesis of the perovskite, a wide variety of procedures has been employed such as vacuum deposition [13], vapor-assisted solution processing [14], atomic layer deposition [15], solution processing in one or two steps [16,17] etc. However, $\mathrm{MAPbl}_{3}$ perovskite materials are still not stable enough in the long term to become fully affordable and scalable. $\mathrm{MAPbl}_{3}$ perovskite materials have been proven to degrade under humid conditions [18], and several techniques have been applied in order to improve stability [19-21]. In this context, it has been found that $\mathrm{MAPbBr}_{3}$ is less sensitive to humidity [22,23], but at the expense of losing absorption properties. Some researchers focused on mixed halide perovskites $\mathrm{MAPbl}_{3-\mathrm{x}} \mathrm{Br}_{\mathrm{x}}$ and $\mathrm{MAPbl}_{3-\mathrm{x}} \mathrm{Cl}_{\mathrm{x}}$ as the substitution of iodine by chloride or bromide atoms leads to a significant improvement of perovskite stability $[24,25]$.

Defect energy levels have been shown to be situated relatively shallow $[26,27]$ and although it had been hypothesized that grain boundaries do not contribute significantly to recombination losses in perovskites, it has been proved that they are much more harmful than previously assumed $[28,29]$. This means that if it were possible to mitigate nonradiative carrier losses, the efficiency of perovskite solar cells could be substantially improved. In order to successfully mitigate such charge carrier losses, recombination pathways within the perovskite and device have been suppressed. Employing additives in perovskite methylammonium lead iodide seems to 
be an efficient method to tune its properties such as defect density and charge carrier lifetime.

Regarding this topic, under-coordinated ions that may exist at grain boundaries and surfaces that can act as charge carrier trap/recombination centers [30,31] have been described.

Different passivation methods have been employed up to now. For example, an iodopentafluorobenzene (IPFB) post-treatment has been used to passivate undercoordinated iodine [30], thiophene and pyridine have been employed to passivate under-coordinated $\mathrm{Pb}$ ions [31] and, recently, $\mathrm{Br}$ and $\mathrm{Cl}$ have been suggested to assist in suppressing recombination and decoupling electron-hole pairs [32,33].

In order to improve performance, the guanidinium organic molecule $\mathrm{CH}_{6} \mathrm{~N}_{3}{ }^{+}$(GA) has been investigated as an additive for dye-sensitized solar cells (DSSCs), in which it serves to passivate $\mathrm{TiO}_{2}$ surfaces. Also, it has been studied as an additive in $\mathrm{MAPbl}_{3}$ in order to improve structure, stability and performance. GA has a larger size (278 pm) than MA (217 pm), which can lead to different perovskite structures and/or behaviors $[36,37]$, therefore it is necessary to investigate the consequences of the GA addition in detail. Some authors suggest that bias-induced motion and hysteric effects might be influenced by the zero-dipole moment of GA $[34,35]$.

Very recently, a passivation effect through partial GA incorporation in perovskite films has been demonstrated [34], obtaining a significant mitigation of nonradiative decay and an enhanced carrier lifetime, high open circuit voltages and improved device performances.

This study presents the structural and optical effects of partial GA incorporation in $\mathrm{MAPbl}_{3}$ perovskite thin films with the aim of increasing and improving the stability of solar cells.

\section{Experimental procedure}

\subsection{Perovskite fabrication}

Guanidinium iodine $\left(\mathrm{CH}_{6} \mathrm{~N}_{3} \mathrm{l}, \mathrm{GAI}\right)$ was purchased from Sigma Aldrich. Crystalline methylammonium iodide $\left(\mathrm{CH}_{3} \mathrm{NH}_{3} \mathrm{l}, \mathrm{MAI}\right)$ powder was synthesized by reacting $0.3 \mathrm{~mol}$ of concentrated hydriodic acid (Sigma Aldrich) with $0.3 \mathrm{~mol}$ of methylamine $\left(\mathrm{CH}_{3} \mathrm{NH}_{2}\right)$ 
solution (33\% in methanol, Sigma Aldrich) whilst being stirred for $2 \mathrm{~h}$ in a $250 \mathrm{~mL}$ round-bottom flask kept in an ice bath $\left(0^{\circ} \mathrm{C}\right)$. The solvent was evaporated at $50{ }^{\circ} \mathrm{C}$ in the rotary evaporator. Then, the precipitate was filtered and recrystallized by solving it in absolute ethanol and precipitating it with the addition of diethyl ether. After this process, pure MAI was obtained.

The films were deposited onto the indium tin oxide (ITO) substrates that were cleaned with soap (2\%, Hellmanex) and rinsed with deionized water. Then, the substrates are rinsed with ethanol, acetone and isopropyl alcohol for 15 min by ultra sonication. After that, the substrates were dried with argon blow.

The $\mathrm{MA}_{1-\mathrm{x}} \mathrm{GA}_{\mathrm{x}} \mathrm{Pbl}_{3}$ films were prepared by mixing stoichiometric ratio of GAI, MAI and $\mathrm{Pbl}_{2}$ (99.9\%, Sigma Aldrich). The precursors were dissolved at $45 \%$ wt in dimethylformamide (DMF) under inert atmosphere in an argon globe box. The solutions were kept under magnetic stirring at $60^{\circ} \mathrm{C}$ for 30 minutes. The films were deposited, inside the globe box, using the spin coating process at $5000 \mathrm{rpm}$ for $20 \mathrm{~s}$, then dried and annealed at $100^{\circ} \mathrm{C}$ for $1 \mathrm{~h}$, for the $\mathrm{MAPbl}_{3}$ samples and at $135^{\circ} \mathrm{C}$ for the MA1-xGAxPbl 3 samples for 15 minutes. These samples were kept in the globe box before analysis.

2.2 Thin film characterization

X-Ray Diffraction:

X-Ray diffraction patterns of perovskite films were obtained by a RIGAKU Ultima IV diffractometer in the Bragg-Bentano configuration using $\mathrm{Cu} \mathrm{K}_{\alpha}$ radiation $(\lambda=1.54060$ $\AA)$.

\section{Absorption Spectroscopy:}

Absorption spectra of perovskites were calculated from the transmittance measurements obtained with an Ocean Optics HR4000 spectrometer equipped with a Si-CCD detector and an integrating sphere to collect specular and diffuse transmittance at room temperature. 
Erika Vega, Miguel Mollar, Bernabé Marí; Journal of Alloys and

Photoluminescence (PL):

Photoluminescence spectra were recorded at low temperature using an HE-closed cryostat. A $325 \mathrm{~nm}$ He-Cd laser was used as PL excitation source. Photoluminescence data were recorded by a Hammamatsu Si-based back-thinned CCD detector.

Field-Emission Scanning Electron Microscopy:

Surface morphology and elemental composition measurements of perovskite film samples were taken using an environmental scanning electron microscope FESEM (Quanta $200-\mathrm{FEI}$ ).

\section{Results and Discussion}

\subsection{X-Ray diffraction}

Fig. 1a presents the diffractograms (XRD) of $\mathrm{MA}_{1-\mathrm{x}} \mathrm{GA}_{\mathrm{x}} \mathrm{Pbl}_{3}$ for different $\mathrm{x}$ values. The $\mathrm{MAPbl}_{3}$ perovskite characteristic peaks are located at approximately $14.1^{\circ}$ and $28.4^{\circ}(2 \theta)$, corresponding to planes 100 and 200 , respectively. These peaks can be observed for the $\mathrm{MAPbl}_{3}$ and $\mathrm{MA}_{1-\mathrm{x}} \mathrm{GA}_{\mathrm{x}} \mathrm{Pbl}_{3}$ samples $(0.1 \leq \mathrm{x} \leq 0.2)$ with a $\mathrm{GA}$ content of up to $20 \%$. When the GA content is above $20 \%$, the $8.4^{\circ}$ and $11.2^{\circ}$ peaks, corresponding to the GA tetragonal phase become visible, indicating the solubility limit has been reached.

To determine the lattice parameter of $\mathrm{GAPbl}_{3}$, a Pawley refinement of the XRD spectra was carried out. A tetragonal lattice type (space group P42_NMC) was found when neglecting the ITO peaks. Fig. 1b shows a good fit between the simulated and the experimental diffractograms.

In order to gain further insight into the GA incorporation, Pawley refinements of the $\mathrm{MA}_{1-\mathrm{x}} \mathrm{GA}_{\mathrm{x}} \mathrm{Pbl}_{3}(\mathrm{x}=0,0.1,0.2) \mathrm{XRD}$ patterns were carried out obtaining a tetragonal lattice type (space group 14_CM) and experimental and simulated data for the 100 peak are shown in Fig. 1c. The addition of GA produces a slight shift toward a lower angle of the characteristic 100 and 200 MA perovskite peaks, located at $14.1^{\circ}$ and at $28.4^{\circ}$, which can be attributed to the fact that GA has a larger volume than MA and the partial substitution produces an increase in the lattice parameter. Table 1 summarizes the results of the Pawley refinements. 
Fig. 1d shows the evolution of the lattice parameters vs GA content $x$. As can be seen, the cell parameter $a$ varies almost linearly, following Vegard's law. However, parameter $c$ slightly increases with a GA content of up to $10 \%$. The abrupt decrease for higher concentrations than $\mathrm{x}=0.15$ indicates a probable lattice change.
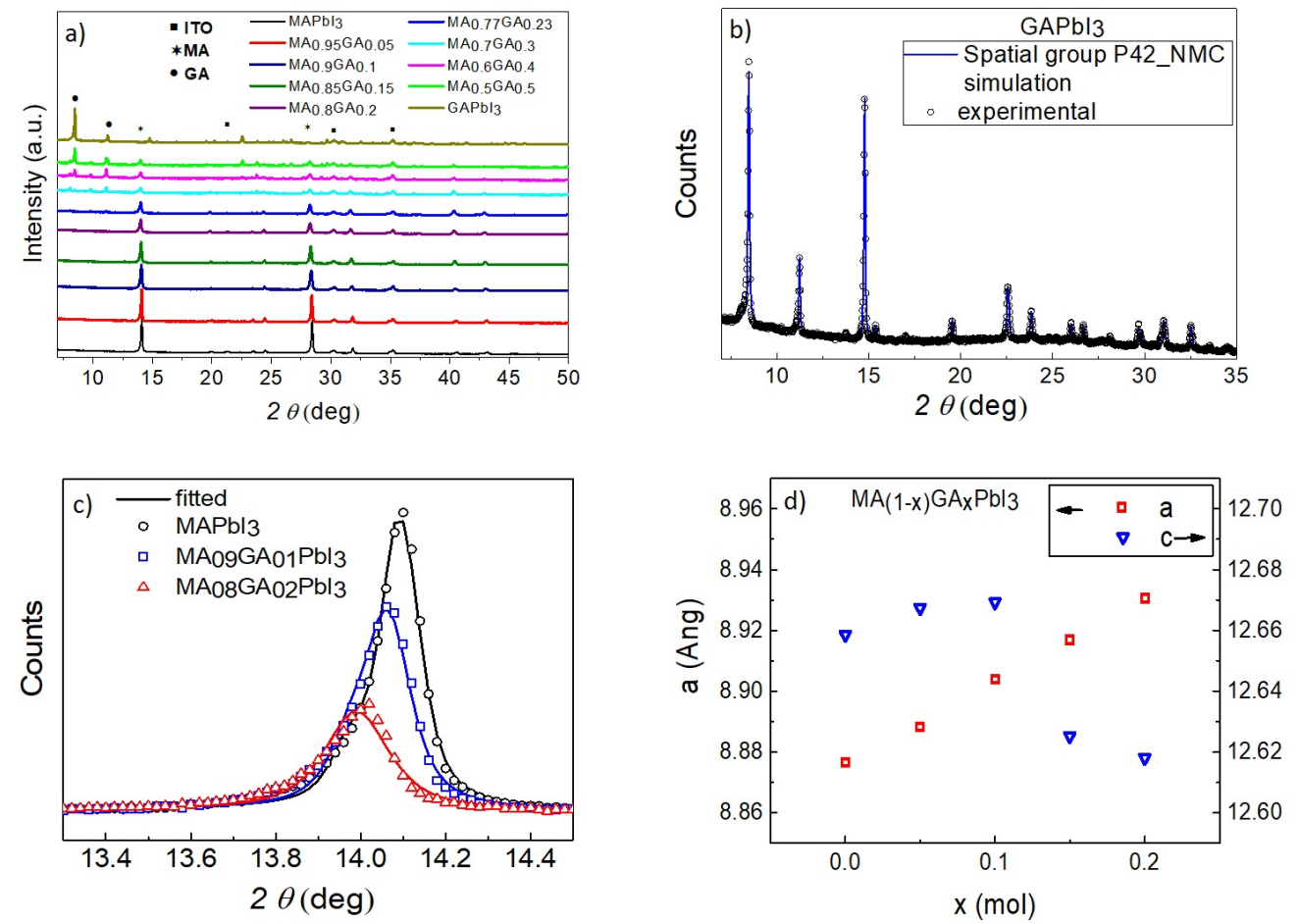

Figure 1. (a) X-ray diffractograms of $M A_{1-x} G_{x} P l_{3}(0 \leq x \leq 1)$, by the spin coating process. (b) XRD spectra for pure $\mathrm{GAPbl}_{3}$ corresponding to the space group tetragonal P42_NMC. (c) XRD patterns of the MAPbl ${ }_{3}$ and $\mathrm{MA}_{1-\mathrm{x}} \mathrm{GA}_{\mathrm{x}} \mathrm{Pbl}_{3}$ with $\mathrm{x}=0.1,0.2$. (d) Composition dependent evolution of lattice parameters as a function of $G A$ content.

Table 1. Refinement factors and refined cell parameters using the Pawley method.

\begin{tabular}{c|c|c|c}
\hline Sample id. & $\mathbf{a}=\mathbf{b}(\AA)$ & $\mathbf{c}(\AA)$ & Rwp \\
\hline $\mathrm{MAPbl}_{3}$ & 8,87659 & 12,65859 & $4,42 \%$ \\
\hline $\mathrm{MA}_{0.9} \mathrm{GA}_{0.1} \mathrm{Pbl}_{3}$ & 8,90393 & 12,66932 & $4,21 \%$ \\
\hline $\mathrm{MA}_{0.8} \mathrm{GA}_{0.2} \mathrm{Pbl}_{3}$ & 8,93066 & 12,61813 & $3.95 \%$ \\
\hline $\mathrm{GAPbl}_{3}$ & 11,97202 & 20,86364 & $5,52 \%$ \\
\hline
\end{tabular}

In order to evaluate the stability of mixed perovskite samples, diffractograms of $\mathrm{MAPbl}_{3}$ and $\mathrm{MA}_{1-\mathrm{x}} \mathrm{GA}_{\mathrm{x}} \mathrm{Pbl}_{3}$ thin films were recorded immediately after sample preparation. These samples were kept at room temperature and humidity for eight 
months before a control diffractogram was made. Fig. 2 shows diffractograms for $\mathrm{MAPbl}_{3}$ and $\mathrm{MA}_{0.9} \mathrm{GA}_{0.1} \mathrm{Pbl}_{3}$ before and after eight months aging, denoted (A) and (B), respectively. As can be seen, the aged pure methylammonium perovskite shows a $12.6^{\circ}$ peak, corresponding to $\mathrm{Pbl}_{2}$, which evidences perovskite decomposition. Nevertheless, the diffractogram of the mixed methylammonium-guanidinium perovskite sample remains unaltered. Samples with a greater GA contents showed $\mathrm{Pbl}_{2}$ and/or GA peaks that evidence decomposition or guanidinium perovskite segregation, as can be seen in Fig. S1.
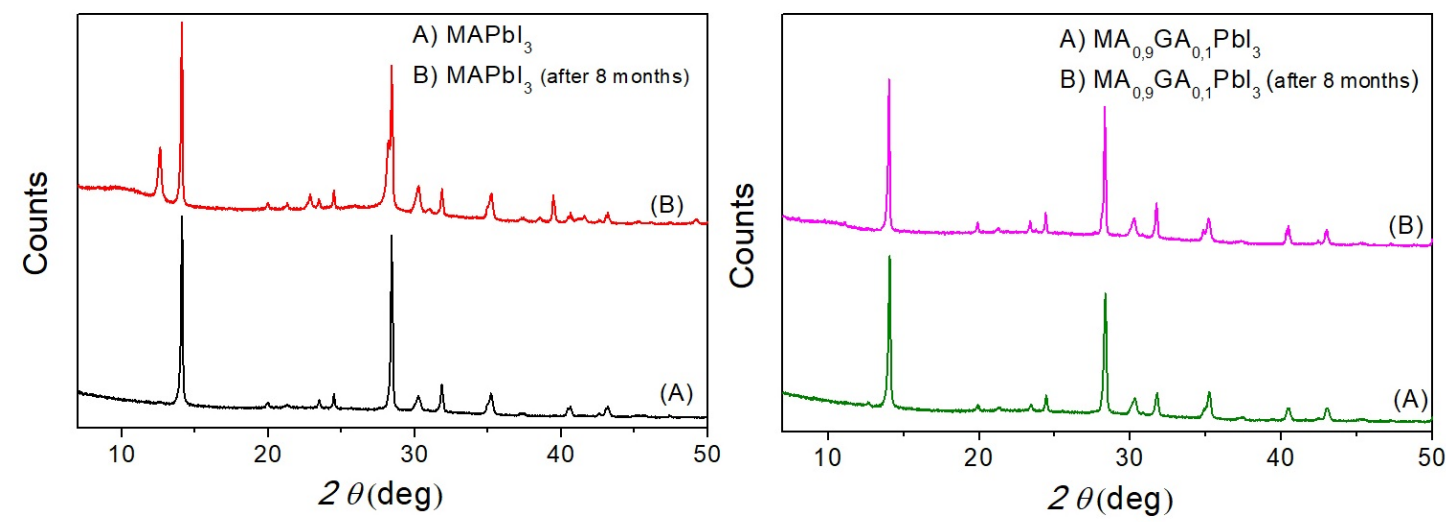

Figure 2. X-ray diffractograms of $\mathrm{MAPbl}_{3}$ and $\mathrm{MA}_{0.9} \mathrm{GA}_{0.1} \mathrm{Pbl}_{3}$ before and after eight months.

\subsection{Absorptance}

Fig. 3a displays the absorption spectra for different GA values. An integrating sphere was used to collect both, specular and diffuse transmittance to reduce the effect of light scattering originated from refraction and reflection phenomena on the perovskite crystals.

The GA fraction contained in $\mathrm{MA}_{1-\mathrm{x}} \mathrm{GA}_{x} \mathrm{Pbl}_{3}$ affects the optical properties. It can easily be appreciated that an increasing amount of GA results in front edge diminution, and therefore a reduction of the absorptance.

Fig. $3 \mathrm{~b}$ provides Tauc plots showing variations in the optical bandgap. It can be observed that for the samples between 0 and $20 \%$, the bandgap evolves very slightly towards lower energies. In Fig. 3a, a decrease of the slope for a GA contents above $20 \%$ can be appreciated, indicating a degradation of the bandgap. This result agrees with the previously suggested lattice change. Figure $3 c$ shows a change of color varying from the black for $\mathrm{MAPbl}_{3}$ to the yellow for $\mathrm{GAPbl}_{3}$. 
Table 2 shows the estimated bandgap (Eg) of $\mathrm{MA}_{1-x} \mathrm{GA}_{x} \mathrm{Pbl}_{3}$, for samples between 0 and $20 \%$ GA contents obtained from the Fig. $3 \mathrm{~b}$. It can be seen that the bandgap remains almost constant, the overall variation between all the samples being 1.59 to $1.60 \mathrm{eV}$, corresponding to absorption edges spanning $775-780 \mathrm{~nm}$. The inset of Fig. 3b shows the estimated bandgap (Eg) for the $\mathrm{GAPbl}_{3}$ sample being $2.62 \mathrm{eV}$, corresponding to an absorption edge of $470 \mathrm{~nm}$.
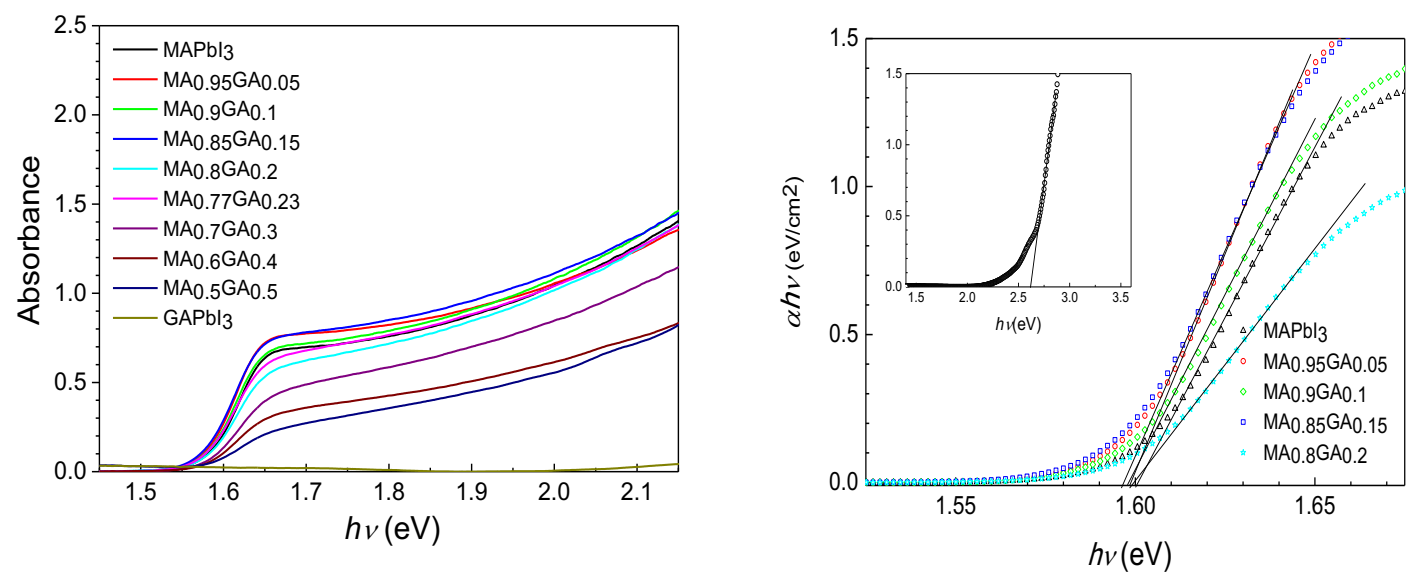

Figure 3. (a) UV-Vis absorption spectra of $\mathrm{MA}_{1-x} \mathrm{GA}_{x} \mathrm{Pbl}_{3}$ for different GA contents. (b) Tauc plots showing variations in optical bandgap.

Table 2. Band gap variation depending on GA content.

\begin{tabular}{c|c|c}
\hline \multirow{2}{*}{ Sample Composition } & \multicolumn{2}{|c}{ Absorption edge at Room T } \\
\cline { 2 - 3 } & (eV) & (nm) \\
\hline $\mathrm{MAPbl}_{3}$ & 1.60 & 775 \\
\hline $\mathrm{MA}_{0.95} \mathrm{GA}_{0.05} \mathrm{Pbl}_{3}$ & 1.59 & 780 \\
\hline $\mathrm{MA}_{0.9} \mathrm{GA}_{0.1} \mathrm{Pbl}_{3}$ & 1.59 & 780 \\
\hline $\mathrm{MA}_{0.85} \mathrm{GA}_{0.15} \mathrm{Pbl}_{3}$ & 1.59 & 780 \\
\hline $\mathrm{MA}_{0.8} \mathrm{GA}_{0.2} \mathrm{Pbl}_{3}$ & 1.59 & 780 \\
\hline $\mathrm{GAPbl}_{3}$ & 2.62 & 470 \\
\hline
\end{tabular}

\subsection{Photoluminescence}

The photoluminescence study at different temperatures illustrates charge carrier dynamics as well as the quality of the material emission. Fig. 4a shows the PL results of $\mathrm{MA}_{1-\mathrm{x}} \mathrm{GA}_{\mathrm{x}} \mathrm{Pbl}_{3}(\mathrm{x}=0,0.15,0.5,1)$ at $11 \mathrm{~K}$. Intensities have been normalized to clarify the shift of the emission peaks. It can easily be observed that the position of the peak 
about $800 \mathrm{~nm}$ for the MA-GA-based samples shifts slightly to higher wavelengths as the GA concentration increases. This behavior could be explained by the bandgap defects introduced by the GA doping. Further research is required to clarify this behavior. Moreover a pure $\mathrm{GAPbl}_{3}$ perovskite shows a single peak located at $565 \mathrm{~nm}$.

For a GA content of $50 \%$, both peaks, at 570 and 810 can be observed, which is indicative of the two phases being present, as be shown in Fig. S2. In agreement with previous results for a GA content above $20 \%$.

$\mathrm{PL}$ intensity of the $\mathrm{MAPbl}_{3}$ and $\mathrm{MA}_{0.85} \mathrm{GA}_{0.15} \mathrm{Pbl}_{3}$ samples at $11 \mathrm{~K}$ is shown in Fig. $4 \mathrm{~b}$. $\mathrm{MA}_{0.85} \mathrm{GA}_{0.15} \mathrm{Pbl}_{3}$ shows a large rise in $\mathrm{PL}$ intensity, more than three times, that of the pure MA samples, as has been described in ref [34]. This improvement in PL can be due to the fact that the incorporation of GA reduces the amount of non-radiative levels and then the recombination takes place through radiative paths, resulting in the aforementioned improvement of PL.

Table 3 displays that the calculated bandgap at different temperatures obtained from PL measurements (Fig S3) increased as the temperature increased, as can be inferred from the evolution of the peaks towards lower wavelengths.

In this table it is worth noting that the gap energy at $11 \mathrm{~K}$ for $\mathrm{MA}_{0.85} \mathrm{GA}_{0.15} \mathrm{Pbl}_{3}$ is inferior to the gap for $\mathrm{MAPbl}_{3}$, nevertheless this may be because the incorporation of GA produces the aforementioned supplementary energy levels above the valence band or conduction band, and the reduction of the gap, as a consequence.
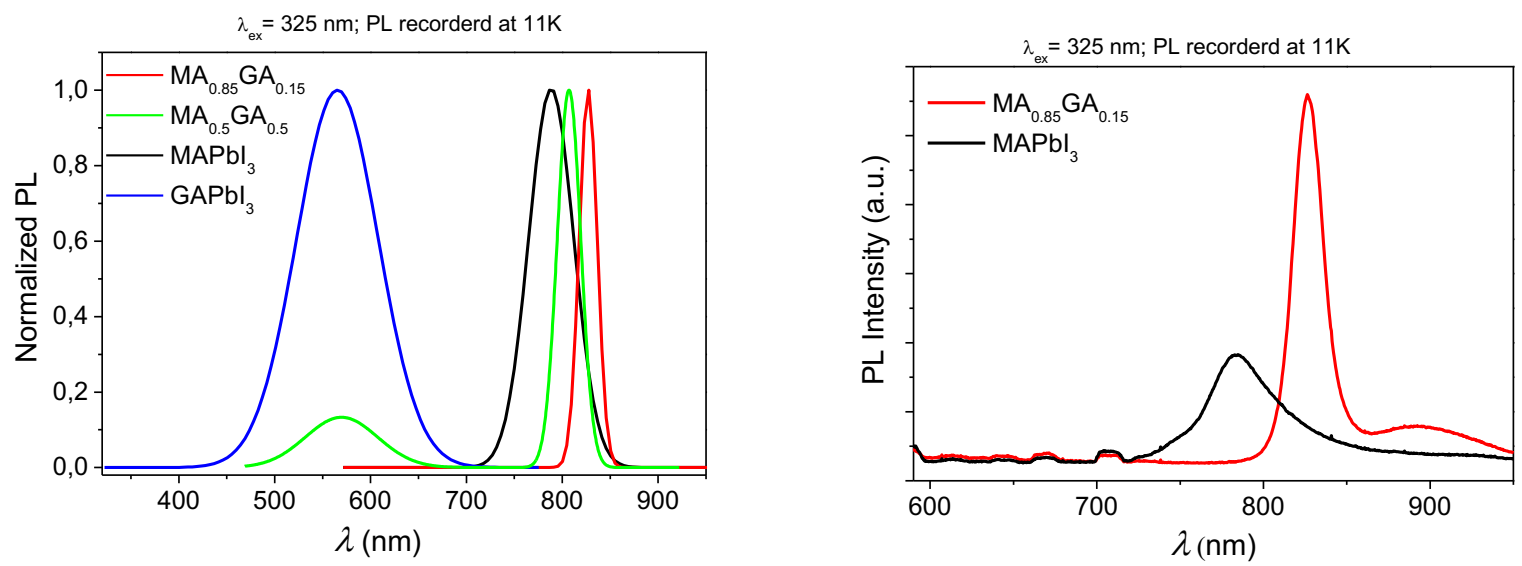

Figure 4. (a) Normalized photoluminescence emissions of $\mathrm{MA}_{1-\mathrm{x}} \mathrm{GA}_{\mathrm{x}} \mathrm{Pbl}$ 作 $\mathrm{x}=0,0.15,0.5,1$ at $11 \mathrm{~K}$. (b) Photoluminescence emissions of $\mathrm{MAPbl}_{3}$ and $\mathrm{MA}_{0.85} \mathrm{GA}_{0.15} \mathrm{Pbl}_{3}$ recorded at $11 \mathrm{~K}$. 
Erika Vega, Miguel Mollar, Bernabé Marí; Journal of Alloys and Compounds, Volume 739, Pages 1059-1064(2018)

https://doi.org/10.1016/j.jallcom.2017.12.177

Table 3. Band gap variation according to temperature and GA content.

\begin{tabular}{c|c|c|c|c|c|c|c|c}
\hline \multirow{2}{*}{$\begin{array}{c}\text { Sample } \\
\text { Composition }\end{array}$} & \multicolumn{2}{|c|}{ PL peak position at $11 \mathrm{~K}$} & \multicolumn{2}{c|}{ PL peak position at 20 K } & \multicolumn{2}{c|}{ PL peak position at 70 K } & \multicolumn{2}{c}{ PL peak position at 100 K } \\
\cline { 2 - 10 } & $(\mathrm{eV})$ & $(\mathrm{nm})$ & $(\mathrm{eV})$ & $(\mathrm{nm})$ & $(\mathrm{eV})$ & $(\mathrm{nm})$ & $(\mathrm{eV})$ & $(\mathrm{nm})$ \\
\hline $\mathrm{MAPbl}_{3}$ & 1.57 & 787 & 1.58 & 785 & 1.58 & 782 & 1.58 & 782 \\
\hline $\mathrm{MA}_{0.85} \mathrm{GA}_{0.15} \mathrm{Pbl}_{3}$ & 1.49 & 827 & 1.51 & 818 & 1.52 & 814 & 1.53 & 809 \\
\hline $\mathrm{MA}_{0.5} \mathrm{GA}_{0.5} \mathrm{Pbl}_{3}$ & 1.53 & 807 & 1.53 & 807 & 1.56 & 795 & 1.56 & 795 \\
\hline $\mathrm{GAPbl}_{3}$ & 2.19 & 565 & 2.21 & 560 & 2.22 & 558 & - & - \\
\hline
\end{tabular}

\subsection{FESEM Analysis}

SEM analysis was conducted in order to examine the impact of GA incorporation on the morphology. Fig. 5 presents top view SEM images of the $M_{1}$ ${ }_{x} \mathrm{GA}_{x} \mathrm{Pbl}_{3}$ perovskite thin films deposited on ITO substrates for $x=0,0.15,0.5,1$. As the amount of GA increases, the layer becomes more homogeneous, although the absorption edges shift to higher energies and then the overall absorption decreases. These results are in agreement with previous results [34].

$\mathrm{MA}_{0.85} \mathrm{GA}_{0.15} \mathrm{Pbl}_{3}$ needle-shape layers can be appreciated, with having a bettercovered and smoother surface. The size of the needle-shape diminishes, increasing the homogeneity.
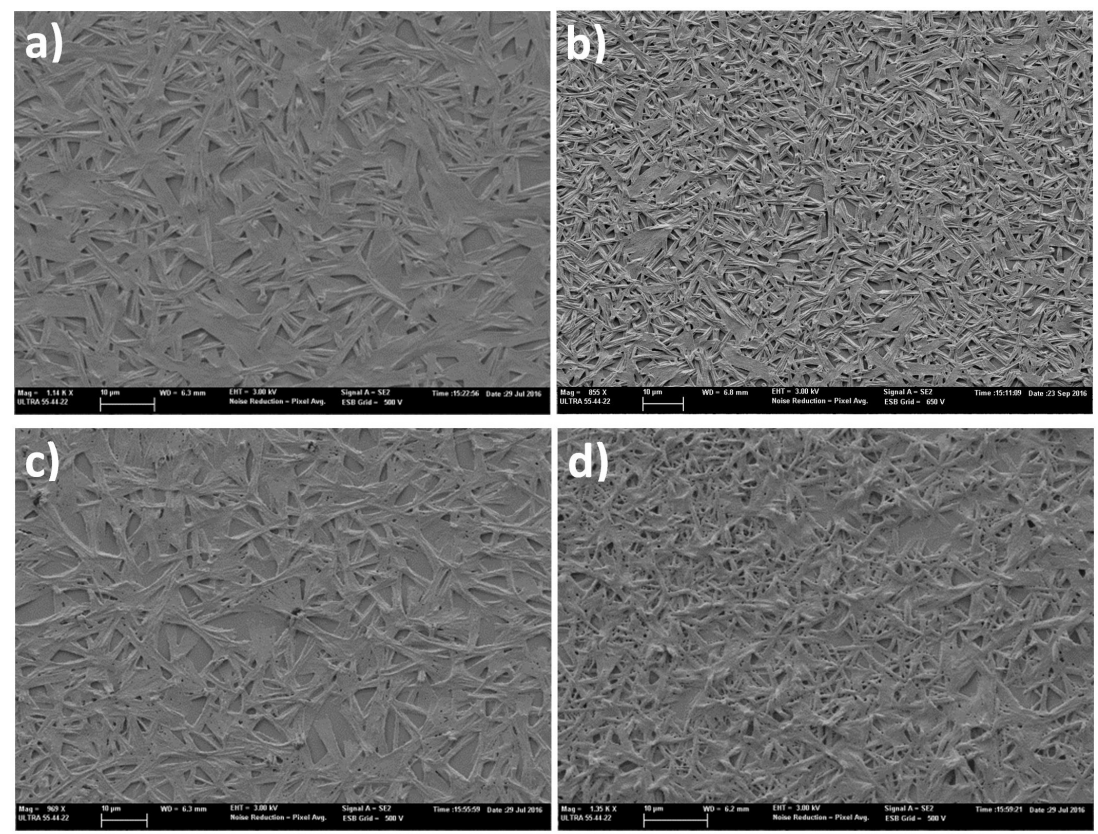

Figure 5. FESEM micrographs of perovskite thin films of (a) $\mathrm{MAPbl}_{3}$, (b) $\mathrm{MA}_{0.85} \mathrm{GA}_{0.15} \mathrm{Pbl}_{3}$, (c) $\mathrm{MA}_{0.5} \mathrm{GA}_{0.5} \mathrm{Pbl}_{3}$ and (d) $\mathrm{GAPbl}_{3}$. 


\section{Conclusions}

This work reports the synthesis of $\mathrm{MA}_{1-\mathrm{x}} \mathrm{GA}_{\mathrm{x}} \mathrm{Pbl}_{3}$ for different $\mathrm{x}$ values under an inert atmosphere, deposited on ITO substrate by spin coating. X-Ray diffraction analysis showed that the $\mathrm{MAPbl}_{3}$ perovskite characteristic peaks were only found in the $\mathrm{MA}_{1-\mathrm{x}} \mathrm{GA}_{\mathrm{x}} \mathrm{Pbl}_{3}$ samples $(0.1 \leq \mathrm{x} \leq 0.2)$, indicating the $\mathrm{GA}$ incorporation in $\mathrm{MAPbl}_{3}$ lattice.

Tetragonal lattice type, space groups P42_NMC and 14_CM, were found for GAPbl 3 and $\mathrm{MAPbl}_{3}$, respectively. When the GA content exceeds $20 \%$, both $\mathrm{MAPbl}_{3}$ and $\mathrm{GAPbl}_{3}$ peaks were present, indicating the solubility limit is reached.

Absorption spectra show that an increase in the GA content affects the optical properties, reducing the absorptance and therefore the light harvesting capability. Samples with a GA content between 0 and $20 \%$ showed a very slight shift towards lower energies, and samples with a GA content above $20 \%$ exhibited a decrease of the slope and, therefore, a degradation of the bandgap. The estimated bandgap (Eg) for the samples with a GA content between 0 and 20\% decreased from 1.60 to $1.59 \mathrm{eV}$, corresponding to absorption edges spanning 775-780 $\mathrm{nm}$.

$\mathrm{PL}$ results of $\mathrm{MA}_{1-\mathrm{x}} \mathrm{GA}_{\mathrm{x}} \mathrm{Pbl}_{3}$ for different values of $\mathrm{x}$ at different temperatures showed that the position of the peaks of the GA-based samples shifts slightly to higher wavelengths as the GA concentration increases. Energy peak decreases can be explained by the bandgap defects introduced by the substitution of MA by GA. Above a GA content of $20 \%$, peaks at 570 and $810 \mathrm{~nm}$ can be observed, which confirms that both phases are present.

SEM analysis images of the $\mathrm{MA}_{1-\mathrm{x}} \mathrm{GA}_{\mathrm{x}} \mathrm{Pbl}_{3}$ perovskite thin films deposited on ITO substrate showed that grain continuity seems to have improved.

\section{Acknowledgments}

Funding: This work was supported by Ministerio de Economía y Competitividad [ENE2016-77798-C4-2-R] and Generalitat Valenciana [Prometeus 2014/044].

\section{References}

[1] A. Kojima, K. Teshima, Y. Shirai, T. Miyasaka, Organometal Halide Perovskites as Visible-Light Sensitizers for Photovoltaic Cells, J. Am. Chem. Soc. 131 (2009) 6050- 
6051. doi:10.1021/ja809598r .

[2] J. Burschka, N. Pellet, S.-J. Moon, R. Humphry-Baker, P. Gao, M.K. Nazeeruddin, M. Grätzel, Sequential deposition as a route to high-performance perovskite-sensitized solar cells, Nature. 499 (2013) 316. doi:10.1038/nature12340 .

[3] L. Etgar, P. Gao, Z. Xue, Q. Peng, A.K. Chandiran, B. Liu, M.K. Nazeeruddin, M. Grätzel, Mesoscopic CH 3 NH 3 PbI 3 /TiO 2 Heterojunction Solar Cells, J. Am. Chem. Soc. 134 (2012) 17396-17399. doi:10.1021/ja307789s .

[4] B. V Lotsch, New Light on an Old Story: Perovskites Go Solar, Angew. Chemie Int. Ed. 53 (2014) 635-637. doi:10.1002/anie.201309368.

[5] N.-G. Park, Organometal Perovskite Light Absorbers Toward a 20\% Efficiency LowCost Solid-State Mesoscopic Solar Cell, J. Phys. Chem. Lett. 4 (2013) 2423-2429. doi:10.1021/jz400892a.

[6] H.J. Snaith, Perovskites: The Emergence of a New Era for Low-Cost, High-Efficiency Solar Cells, J. Phys. Chem. Lett. 4 (2013) 3623-3630. doi:10.1021/jz4020162.

[7] W. Shockley, H.J. Queisser, Field enhanced donor diffusion in degenerate semiconductor layers, J. Appl. Phys. 32 (1961) 510-519.

[8] H.-S. Kim, C.-R. Lee, J.-H. Im, K.-B. Lee, T. Moehl, A. Marchioro, S.-J. Moon, R. Humphry-Baker, J.-H. Yum, J.E. Moser, M. Grätzel, N.-G. Park, Lead Iodide Perovskite Sensitized All-Solid-State Submicron Thin Film Mesoscopic Solar Cell with Efficiency Exceeding 9\%, Sci. Rep. 2 (2012). doi:10.1038/srep00591 .

[9] S.D. Stranks, G.E. Eperon, G. Grancini, C. Menelaou, M.J.P. Alcocer, T. Leijtens, L.M. Herz, A. Petrozza, H.J. Snaith, Electron-hole diffusion lengths exceeding 1 micrometer in an organometal trihalide perovskite absorber, Science 342 (2013) 341-344.

[10] R. Dhanker, A.N. Brigeman, A. V Larsen, R.J. Stewart, J.B. Asbury, N.C. Giebink, Random lasing in organo-lead halide perovskite microcrystal networks, Appl. Phys. Lett. 105 (2014). doi:10.1063/1.4898703 .

[11] H.J. Snaith, M. Gratzel, Electron and hole transport through mesoporous TiO2 infiltrated with spiro-MeOTAD, Adv. Mater. 19 (2007) 3643-3647.

[12] Research Cell Efficiency Records, NREL http://www.nrel.gov/ncpv/images/efficiencychart.jpg (accessed 19 July 2017).

[13] M. Liu, M.B. Johnston, H.J. Snaith, Efficient planar heterojunction perovskite solar cells by vapour deposition, Nature. 501 (2013) 395. doi:10.1038/nature12509 .

[14] Q. Chen, H. Zhou, Z. Hong, S. Luo, H.-S. Duan, H.-H. Wang, Y. Liu, G. Li, Y. Yang, Planar heterojunction perovskite solar cells via vapor-assisted solution process, J. Am. Chem. Soc. 136 (2014) 622-625. doi:10.1021/ja411509g .

[15] B.R. Sutherland, S. Hoogland, M.M. Adachi, P. Kanjanaboos, C.T.O. Wong, J.J. McDowell, J. Xu, O. Voznyy, Z. Ning, A.J. Houtepen, E.H. Sargent, Perovskite Thin 
Films via Atomic Layer Deposition.(Report), $27 \quad$ (2015) 53-58. doi:10.1002/adma.201403965 .

[16] M. Lee, J. Teuscher, T. Miyasaka, T.N. Murakami, H.J. Snaith, Efficient hybrid solar cells based on meso-Superstructured organometal halide perovskites, Science 338 (2012) 643-647.

[17] J.M. Ball, M.M. Lee, A. Hey, H.J. Snaith, Low-temperature processed mesosuperstructured to thin-film perovskite solar cells, Energy Environ. Sci. 6 (2013) 17391743. doi:10.1039/c3ee40810h .

[18] A. Dualeh, P. Gao, S. Il Seok, M.K. Nazeeruddin, M. Grätzel, Thermal Behavior of Methylammonium Lead-Trihalide Perovskite Photovoltaic Light Harvesters, Chem. Mater. 26 (2014) 6160-6164. doi:10.1021/cm502468k .

[19] Y. Xiao, G. Han, Y. Chang, H. Zhou, M. Li, Y. Li, An all-solid-state perovskitesensitized solar cell based on the dual function polyaniline as the sensitizer and P-type hole-transporting material, J. Power Sources 267 (2014) 1-8.

[20] S.N. Habisreutinger, T. Leijtens, G.E. Eperon, S.D. Stranks, R.J. Nicholas, H.J. Snaith, Carbon nanotube/polymer composites as a highly stable hole collection layer in perovskite solar cells, Nano Lett. 14 (2014) 5561. doi:10.1021/n1501982b .

[21] I. Hwang, I. Jeong, J. Lee, M.J. Ko, K. Yong, Enhancing Stability of Perovskite Solar Cells to Moisture by the Facile Hydrophobic Passivation, ACS Appl. Mater. \&amp; Interfaces. 7 (2015) 17330. doi:10.1021/acsami.5b04490 .

[22] Z. Cheng, J. Lin, Layered organicinorganic hybrid perovskites: structure, optical properties, film preparation, patterning and templating engineering, CrystEngComm. 12 (2010) 2646-2662. doi:10.1039/c001929a .

[23] G. Niu, W. Li, F. Meng, L. Wang, H. Dong, Y. Qiu, Study on the stability of $\mathrm{CH} 3 \mathrm{NH} 3 \mathrm{PbI} 3$ films and the effect of post-modification by aluminum oxide in all-solidstate hybrid solar cells, J. Mater. Chem. A. 2 (2013) 705-710. doi:10.1039/c3ta13606j .

[24] H.-L. Hsu, C.-C. Chang, C.-P. Chen, B.-H. Jiang, R.-J. Jeng, C.-H. Cheng, Highperformance and high-durability perovskite photovoltaic devices prepared using ethylammonium iodide as an additive, J. Mater. Chem. A. 3 (2015) 9271-9277. doi: $10.1039 / \mathrm{c} 5 \mathrm{ta} 01563 \mathrm{~d}$.

[25] L. Atourki, E. Vega, B. Marí, M. Mollar, H. Ait Ahsaine, K. Bouabid, A. Ihlal, Role of the chemical substitution on the structural and luminescence properties of the mixed halide perovskite thin MAPbI3 - x Br x $(0<=\mathrm{x}<=1)$ films, Appl. Surf. Sci. 371 (2016) 112-117. doi:10.1016/j.apsusc.2016.02.207.

[26] W.-J. Yin, T. Shi, Y. Yan, Unusual defect physics in CH 3 NH 3 PbI 3 perovskite solar cell absorber, Appl. Phys. Lett. 104 (2014) 63903. doi:10.1063/1.4864778 .

[27] J. Kim, S.-H. Lee, J.H. Lee, K.-H. Hong, The Role of Intrinsic Defects in 
Methylammonium Lead Iodide Perovskite, J. Phys. Chem. Lett. 5 (2014) 1312-1317. doi:10.1021/jz500370k .

[28] de Quilettes, D. W.; Vorpahl, S. M.; Stranks, S. D.; Nagaoka, H.; Eperon, G. E.; Ziffer, M. E.; Snaith, H. J.; Ginger, D. S. Solar cells. Impact of microstructure on local carrier lifetime in perovskite solar cells. Science 348 (2015) 683-686.

[29] M.L. Agiorgousis, Y.-Y. Sun, H. Zeng, S. Zhang, Strong Covalency-Induced Recombination Centers in Perovskite Solar Cell Material CH 3 NH 3 PbI 3, J. Am. Chem. Soc. 136 (2014) 14570-14575. doi:10.1021/ja5079305 .

[30] Abate, A.; Saliba, M.; Hollman, D. J.; Stranks, S. D.; Wojciechowski, K.; Avolio, R.; Grancini, G.; Petrozza, A.; Snaith, H. J. Supramolecular halogen bond passivation of organic-inorganic halide perovskite solar cells. Nano Lett. 14(6) (2014) 3247-3254.

[31] Noel, N. K.; Abate, A.; Stranks, S. D.; Parrott, E. S.; Burlakov, V. M.; Goriely, A.; Snaith, H. J. Enhanced photoluminescence and solar cell performance via Lewis base passivation of organic-inorganic lead halide perovskites. ACS Nano 8(10) (2014) 9815-9821.

[32] Yin, W.-J.; Chen, H.; Shi, T.; Wei, S.-H.; Yan, Y. Origin of High Electronic Quality in Structurally Disordered $\mathrm{CH} 3 \mathrm{NH} 3 \mathrm{PbI} 3$ and the Passivation Effect of $\mathrm{Cl}$ and $\mathrm{O}$ at Grain Boundaries. Adv. Electron. Mater. 2015, DOI: 10.1002/aelm.201500044.

[33] G.Y. Kim, S.H. Oh, B.P. Nguyen, W. Jo, B.J. Kim, D.G. Lee, H.S. Jung, Efficient Carrier Separation and Intriguing Switching of Bound Charges in Inorganic-Organic Lead Halide Solar Cells, J. Phys. Chem. Lett. 6 (2015) 2355-2362. doi:10.1021/acs.jpclett.5b00967.

[34] N. De Marco, H. Zhou, Q. Chen, P. Sun, Z. Liu, L. Meng, E.-P. Yao, Y. Liu, A. Schiffer, Y. Yang, Guanidinium: A Route to Enhanced Carrier Lifetime and Open-Circuit Voltage in Hybrid Perovskite Solar Cells, Nano Lett. 16 (2016) 1009-1016. doi:10.1021/acs.nanolett.5b04060.

[35] G. Giorgi, K. Yamashita, Zero-dipole molecular organic cations in mixed organicinorganic halide perovskites: possible chemical solution for the reported anomalous hysteresis in the current-voltage curve measurements, Nanotechnology. 26 (2015) 442001. doi:10.1088/0957-4484/26/44/442001.

[36] G. Kieslich, S. Sun, A.K. Cheetham, Solid-state principles applied to organicinorganic perovskites: new tricks for an old dog, Chem. Sci. 5 (2014) 4712-4715. doi:10.1039/c4sc02211d.

[37] M. Szafraski, M. Jarek, Origin of spontaneous polarization and reconstructive phase transition in guanidinium iodide, CrystEngComm. 15 (2013) 4617-4623. doi:10.1039/c3ce26979e. 